\title{
Initiation on chromatin templates in a yeast RNA polymerase II transcription system
}

\author{
Yahli Lorch, Janice W. LaPointe, and Roger D. Kornberg \\ Department of Cell Biology, Stanford University School of Medicine, Stanford, California 94305 USA
}

\begin{abstract}
Templates were prepared with either the TATA box or transcription start sites of the yeast CYC1 promoter in a nucleosome. In both cases, initiation in an unfractionated yeast RNA polymerase II transcription system was abolished by the nucleosome. The inhibition appeared to be relieved by the activator protein Gal4-VP16 binding to a site upstream of the promoter. Inhibition was not relieved, however, in a transcription system reconstituted from purified components, indicating a requirement for additional factors for the effect of Ga14-VP16.
\end{abstract}

[Key Words: Polymerase II transcription system; chromatin templates; yeast; CYC1 promoter]

Received June 2, 1992; revised version accepted September 15, 1992.

Nucleosomes inhibit the initiation of transcription /for review, see Grunstein 1990; Felsenfeld 1992; Kornberg and Lorch 1991). Early studies revealing this inhibition employed nucleosomes assembled at random on tem. plate DNA (Williamson and Felsenfeld 1978; Wasylyk et al. 1979; Knezetic and Luse 1986). In later experiments a nucleosome was placed precisely on the adenoviral major late promoter or on a bacteriophage promoter, and initiation was abolished (Lorch et al. 1987). The inhibition was the result of the location of the nucleosome and not a nonspecific effect of the histones on transcription, as a nucleosome placed downstream of a promoter allowed initiation and even the passage of polymerase molecules. Similar inhibition of initiation by nucleosomes in vivo was inferred from experiments in which histone synthesis was arrested during a round of DNA replication. Consequent nucleosome loss activated transcription of a repressed gene to about half the extent achieved on full physiologic induction (Han and Grunstein 1988).

How is inhibition by nucleosomes relieved during normal induction of transcription? Binding of human transcription factor IID (TFIID) to the TATA box of the adenoviral major late promoter before nucleosome assem. bly was shown to allow subsequent transcription (Workman and Roeder 1987). Activator proteins present during nucleosome assembly stimulated transcription, apparently by enhancing the ability of TFIID to compete with nucleosomes for binding to a promoter (Workman et al. 1988, 1990). Activator proteins present during nucleosome assembly have also been reported to allow transcription by general initiation factors and polymerase added after assembly (Workman et al. 1991) and to relieve inhibition of transcription by histone $\mathrm{Hl}$
(Croston et al. 1991). Experiments in which nucleosomes were preformed on a promoter and activator protein then added have failed, however, to reveal any relief of inhibition (Laybourn and Kadonaga 1991).

Might activator proteins overcome the inhibitory effects of histones by disrupting the structure of the nucleosome or by dislodging histones from DNA? Many promoters become exposed in nucleosome-free regions upon the induction of transcription in vivo (Gross and Garrard 1988; Elgin 1988). Formation of these regions may begin with the disruption of a single nucleosome, as in the case of glucocorticoid induction of transcription of the mouse mammary tumor virus promoter (RichardFoy and Hager 1987; Bresnick et al. 1992). Alteration in structure of a nucleosome from residues 60 to $250 \mathrm{bp}$ upstream of the promoter exposes a binding site $75 \mathrm{bp}$ upstream for nuclear factor I, whose action is important for transcription.

How much of a promoter must be unmasked to allow the initiation of transcription? In previous experiments in which a nucleosome was placed on the adenoviral major late promoter, the TATA box and transcription start site were only $25 \mathrm{bp}$ apart, and both lay within the core region of the nucleosome (Lorch et al. 1987). We have now taken advantage of the greater distance between TATA box and start sites of yeast promoters to place a nucleosome on one or the other and examine the effects on transcription. Such nucleosomal templates could be used further to investigate the relief of inhibition by activator proteins. We pursued this aspect in a yeast RNA polymerase II transcription system, which is advantageous owing to the availability of mutations in the histones and other proteins involved in the activation process (Grunstein 1990) and also to the recent iso- 
lation of all general initiation factors and RNA polymerase II in pure or highly enriched form (Edwards et al. 1990; Feaver et al. 1991; Henry et al. 1992; Sayre et al. 1992a,b; Tsochner et al. 1992). Our results are significant in two respects: first, we demonstrate the capacity of an activator protein to relieve inhibition of transcription by a nucleosome previously formed and precisely located on a promoter; second, we show that this activation process requires factors beyond those involved in transcription of naked DNA.

\section{Results}

\section{Nucleosomal templates for transcription}

A template with a nucleosome on the TATA box was prepared from the yeast CYC1 promoter fused to a 379 bp G-less cassette (Fig. 1A). The promoter was cleaved with Avall between the TATA box and the two transcription start sites in the cassette. The TATA-containing piece was joined to a nucleosome-positioning sequence, yielding a fragment of $193 \mathrm{bp}$, in which the

\section{A}

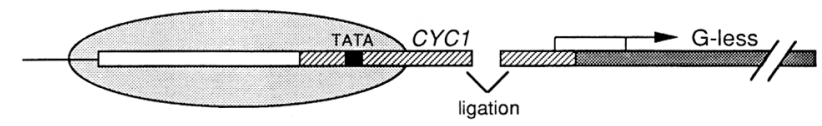

B

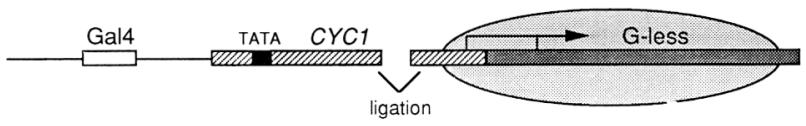

Figure 1. Nucleosomal templates for transcription. $(A)$ Nucleosome on TATA box. N7, a 193-bp DNA fragment, containing $33 \mathrm{bp}$ of vector sequence (thin line), $86 \mathrm{bp}$ of nucleosome positioning sequence (open box; Ramsay 1986; Lorch et al. 1987), and residues -136 to -66 of the yeast CYC1 promoter (hatched box; McNeil and Smith 1985), with the TATA box (solid box) at residues -121 to -113 , was assembled in a nucleosome (lightly stippled oval; position as determined by Ramsay 1986). Ligation to a 416-bp fragment, containing residues -66 to -35 of the CYC1 promoter (hatched box) fused to a 379-bp G-less cassette (darkly stippled box; Sawadogo and Roeder 1985b; Lue et al. 1989), with start sites for transcription in vitro at approximately residue -43 of the promoter and within the G-less cassette $\sim 22$ bp from the point of fusion with the promoter, yielded the template for transcription. $(B)$ Nucleosome on transcription start sites. N8, a 166-bp fragment, identical with the 415-bp fragment in $A$ except with only 136 rather than 379 bp of G-less sequence, was assembled in a nucleosome (lightly stippled oval; position determined from DNase I footprint in Fig. 3). Ligation to a 161bp fragment, containing $33 \mathrm{bp}$ of vector sequence (thin line), a 22-bp Gal4-binding oligonucleotide (open box), $33 \mathrm{bp}$ of vector sequence (thin line), and residues -136 to -66 of the CYC1 promoter (hatched box) yielded the template for transcription.

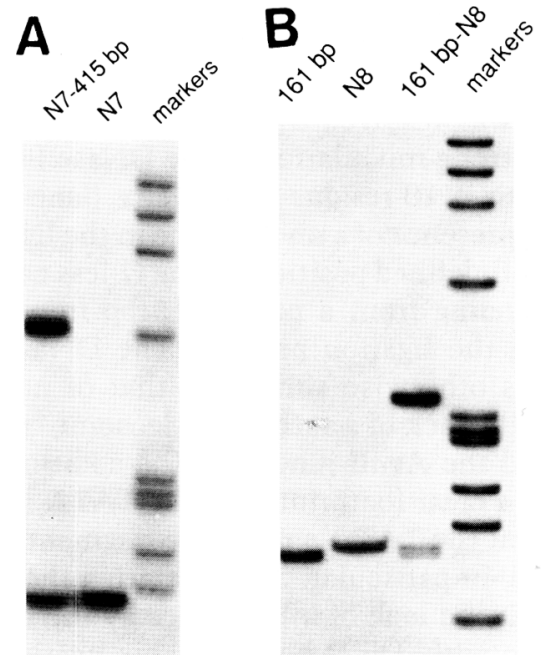

Figure 2. Ligation to form nucleosomal templates for transcription. DNA fragments, nucleosomes used in ligation reactions, and ligated products were deproteinized and analyzed in $4 \%$ polyacrylamide gels as described. Markers were ${ }^{32} \mathrm{P}$-labeled HaeIII fragments of $\Phi \times 174$. Autoradiographs of the gels are shown. (A) N7, ( ${ }^{32} \mathrm{P}$-labeled), bearing a nucleosome, was ligated to a 415-bp fragment (unlabeled). (B) N8, bearing a nucleosome, was ligated to a 161-bp fragment (both fragments were ${ }^{32} \mathrm{P}-1 \mathrm{a}$ beled).

TATA box was located $48-56$ bp from the AvaII end. A nucleosome formed on this fragment must be located on the TATA box, owing to the small size of the fragment, not much larger than the 146-bp length in a nucleosome core particle. Inclusion of a positioning sequence improved stability of the nucleosome, which was otherwise partially labile under the conditions used (not shown). Nucleosomes were assembled by the addition of histone octamers in $2 \mathrm{M} \mathrm{NaCl}$ and dilution to lower ionic strength, isolated by sucrose gradient sedimentation, and ligated to the AvaII fragment, containing transcription start sites and G-less cassette. Ligation was extensive, as shown by the conversion of more than half of the 193-bp fragment bearing the nucleosome to the expected product of 608 bp (Fig. 2A). The ligation mixture could be used directly in transcription reactions, because only the ligation product contained both TATA box and transcription start sites and could serve as a template, whereas unligated nucleosomes or the start site fragment would fail to contribute to the reaction.

A template with a nucleosome covering the transcription initiation region was prepared with the use of a 166bp fragment extending from the AvaII site in the CYC1 promoter to a point $136 \mathrm{bp}$ into the G-less cassette (Fig. 1B). Nucleosome assembly and isolation was as described above, followed by ligation to a 161-bp AvaII fragment of CYC1 promoter DNA containing both the TATA box and, 50 bp upstream, a binding site for the yeast activator protein Gal4 . Ligation was nearly complete, with conversion of almost all of the 166-bp fragment bearing the nucleosome to the expected size of 327 
bp (Fig. 2B); but because the two fragments that were ligated were nearly the same size, they might have been ligated to themselves rather than to one another. This ambiguity was resolved by DNase I footprint analysis (Fig. 3). A strong modulation of the DNase I-cutting frequency with a 10-residue periodicity (lane 1) demonstrated the presence of a nucleosome in the ligation product, in a well-defined position on the G-less cassette fragment, extending from a point $\sim 15 \mathrm{bp}$ from the AvalI junction in the ligation product. The DNase I-cutting pattern was otherwise similar to that of naked DNA, indicating the lack of a second nucleosome or other protein beyond the AvaII junction. The addition of TFIID resulted in a clear footprint over the TATA box, further showing that the TATA-containing fragment was free of protein and, in particular, demonstrating the accessibility to TFIID and lack of interference by the neighboring nucleosome with TFIID binding. This ligation product, like that described above, could be used directly in transcription, because unligated fragments would lack either TATA box or start sites and would therefore fail to support any reaction.

\section{A nucleosome on either TATA box or transcription start site blocks initiation by yeast RNA polymerase II}

The nucleosomal templates described above were transcribed with an unfractionated yeast RNA polymerase II transcription system, because factors required for the reaction with these templates might be lost during fractionation. The results were clear-cut (Fig. 4). Neither the template with a nucleosome on the TATA box nor that with a nucleosome on the start sites supported detectable transcription. In contrast, naked DNA extracted from both templates yielded abundant transcripts of the expected size.

\section{An activator protein relieves inhibition of initiation on a nucleosomal template}

The template with an exposed Gal4-binding site and a nucleosome covering transcription start sites was used to investigate the effect of an activator protein. As shown previously in the human (HeLa) system (Workman et al. 1991), addition of the activator Gal4-VP16 appeared to relieve inhibition of initiation by a nucleosome in the yeast system (Fig. 5A). The level of transcription in the presence of activator in the yeast system was $64 \%$ of that obtained with a naked DNA template. A possible source of artifact would be the contamination of the nucleosomal template by naked DNA, owing to the instability of the nucleosome under the conditions of storage or manipulation. The amount of naked DNA was determined by gel electrophoresis under nondenaturing conditions and was typically $\sim 5 \%$ of that in nucleosomal form. When twice that amount of naked DNA was tested as a control, the level of transcription with Gal4VP16 was $31 \%$ of that obtained from the nucleosomal template preparation, further indicating that a contami-

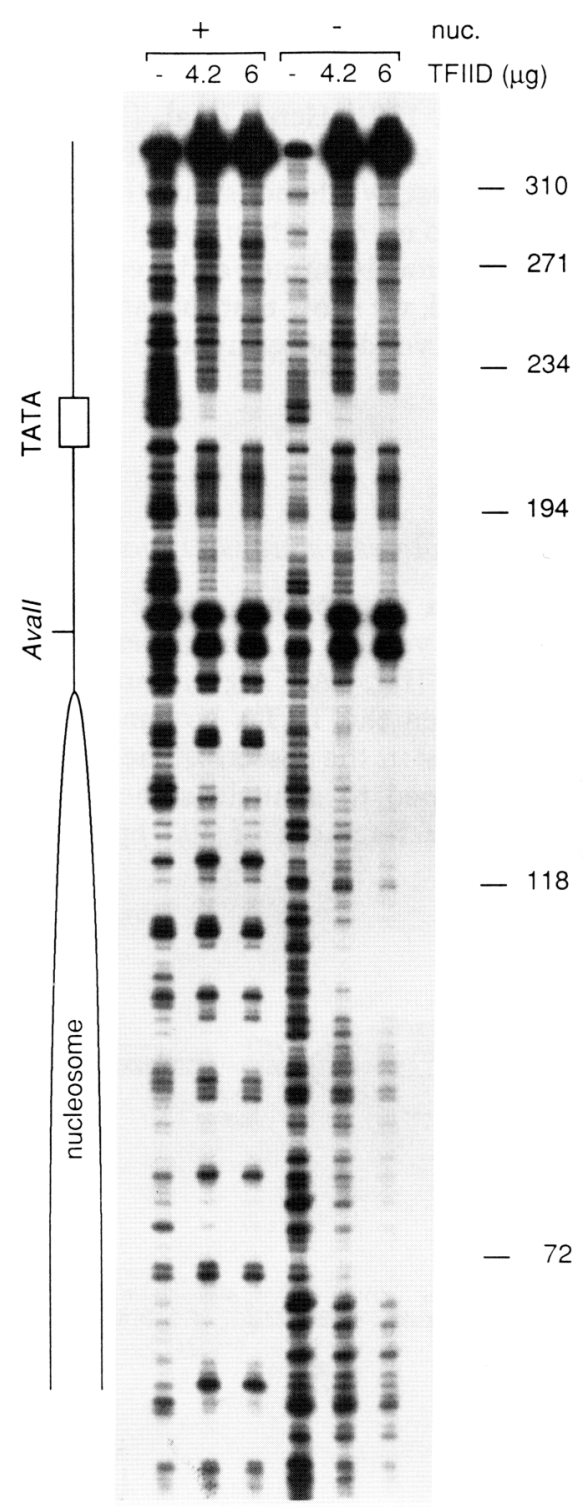

Figure 3. DNase I footprint analysis of template with nucleosome on transcription start sites (N8 bearing a nucleosome, ligated to 161-bp fragment; Fig. 1B). TFIID was added in the amounts indicated to the nucleosomal template (+ nuc., $40 \mathrm{ng}$ of DNA) or to the corresponding naked DNA ( - nuc., $40 \mathrm{ng}$ of DNA) in $20 \mu \mathrm{l}$ of $25 \mathrm{~mm}$ HEPES (pH 7.4), $50 \mathrm{~mm} \mathrm{KCl}, 5 \mathrm{~mm}$ $\mathrm{MgCl}_{2}$, and $0.1 \mathrm{mM}$ EDTA containing $0.75 \mu \mathrm{g}$ of poly[d(I-C)] and $2.5 \mu \mathrm{g}$ of bovine serum albumin. After incubation for $10 \mathrm{~min}$ at $30^{\circ} \mathrm{C}$ and treatment with DNase I 3 and $15 \mathrm{ng}$ for samples without and with TFIID, respectively) for $30 \mathrm{sec}$ at $20^{\circ} \mathrm{C}$, EDTA was added to a concentration of $10 \mathrm{mM}$, and DNA was phenol extracted, dissolved in sequencing gel loading buffer (U.S. Biochemical), and subjected to electrophoresis in a $7 \mathrm{M}$ urea-5\% LONG RANGER (AT Biochemicals) gel in TBE buffer. An autoradiograph of the gel is shown. The structure of the nucleosomal template diagramed at left is from Fig. 1B. Positions of markers run in the same gel are indicated (in nucleotides) at right.

nant of naked DNA was unlikely to be responsible for the results with the nucleosomal preparation. 


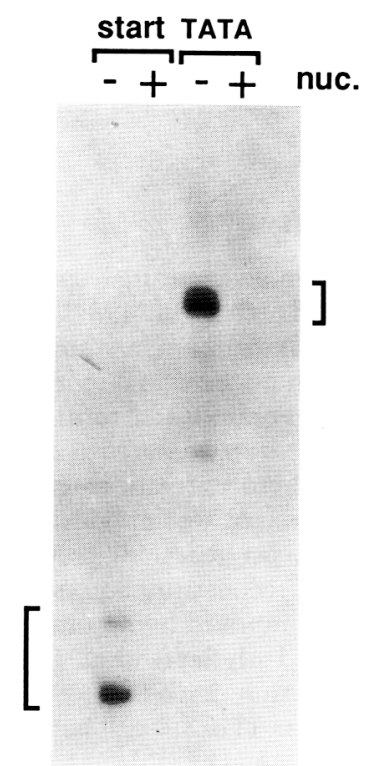

Figure 4. Transcription of nucleosomal templates in unfractionated yeast RNA polymerase II transcription system. Templates with nucleosomes (+ nuc.) on the TATA box (TATA; Fig. 1A; $13 \mathrm{ng}$ of DNA) or on transcription start sites (start; Fig. 1B; $45 \mathrm{ng}$ of DNA), and the corresponding naked DNAs (- nuc.), were transcribed, and the transcripts were processed as described. Brackets indicate transcripts initiating at the two start sites shown in Fig. 1. The transcripts from the short G-less cassette on the left are well separated, whereas those from the longer cassette on the right have not migrated as far and therefore are barely resolved.

Activation of transcription by Gal4-VP16 with naked DNA templates was shown previously to require a protein factor termed mediator, in addition to RNA polymerase II and the general initiation factors /Kelleher et al. 1990; Flanagan et al. 1991). To investigate the involvement of such additional factors in the relief of inhibition due to nucleosomes, transcription was performed with purified polymerase and general initiation factors rather than with an unfractionated system (Fig. 5B). Naked DNA was transcribed by the purified components, and the reaction was stimulated twofold by Gal4-VP16 (the modest stimulation presumably reflecting the presence of a limiting amount of mediator in the reconstituted system). In contrast, the nucleosomal template yielded few transcripts, and the addition of Gal4 VP16 was without effect. Therefore, relief of inhibition due to nucleosomes apparently does require factors in addition to those necessary for initiation on naked DNA.

The factors required for transcription of nucleosomal templates may be defined by fractionation. Work done to date indicates that one essential factor can be enriched by adsorption to Bio-Rex 70 and elution with $0.6 \mathrm{M} \mathrm{po-}$ tassium acetate. Further studies are needed to establish the relationship of the factor to the mediator of transcriptional activation.

\section{Discussion}

Our finding that TFID binding to a template with a nu- cleosome on the transcription start site fails to support initiation must be reconciled with previous reports that TFIID binding during nucleosome assembly does allow subsequent transcription (see introductory section). The reason for the discrepancy may lie in the difference in size between yeast TFIID, a monomer of $27 \mathrm{kD}$, and mammalian TFIID, an oligomer of $\sim 750 \mathrm{kD}$ (Conaway and Conaway 1991). The footprint of yeast TFIID on the adenoviral major late promoter includes only 4 residues on either side of the TATA box (TATAAAA, residues -31 to -25 , with respect to the start site at +1 ), whereas the footprint of human TFIID extends from residue -45 upstream of the TATA box to residue +35 downstream of the transcription start site (Sawadogo and Roeder 1985a). Binding of human TFIID would therefore be expected to prevent nucleosome assembly on both the TATA box and the transcription start site, consistent with the requirement that both be available for transcription.

The capacity of a nucleosome on either the TATA box or start site to block initiation may be pertinent to the repression of transcription of some genes in vivo. For example, fine mapping of the chromatin structure of the yeast GAL1-GAL10 intergenic region in the transcriptionally inactive state reveals a nucleosome on the start

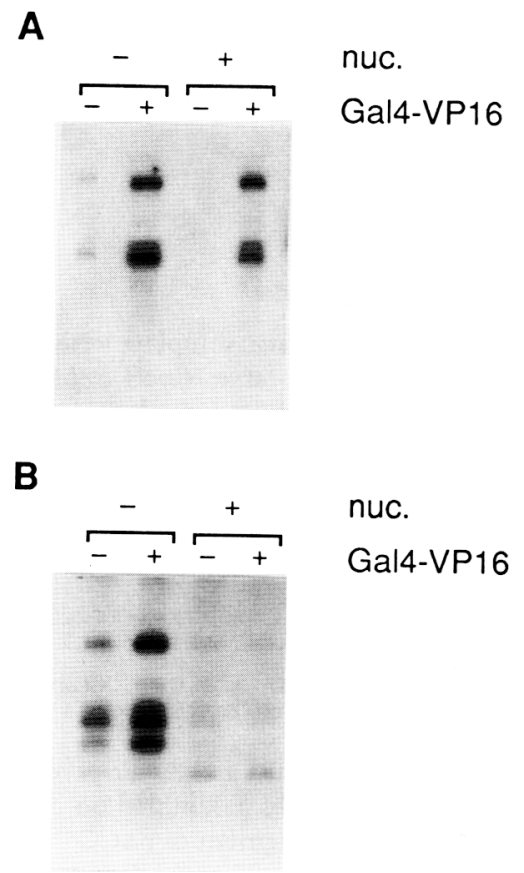

Figure 5. Activation of transcription of nucleosomal templates by Gal4-VP16 in unfractionated $(A)$ and reconstituted $(B)$ yeast RNA polymerase II transcription systems. The template with a nucleosome (+ nuc.) on transcription start sites (Fig. 1B; $6.5 \mathrm{ng}$ of DNA) and the corresponding naked DNA ( - nuc.) were transcribed in the presence $(+)$ or absence $(-)$ of Gal4-VP16, and the transcripts were processed as described. Radioactivity in specific transcripts was (from left to right) relative to that in the second lane, in $A, 11,100,0$, and $64 \%$; and in $B, 52,100,16$, and $9 \%$. 
site but not the TATA box of the GAL1 promoter and the reverse for the GAL10 promoter (Fedor and Kornberg 1988). The present work indicates that nucleosomes inhibit initiation at both promoters and, further, that Gal 4 protein, the activator for these promoters, somehow overcomes the inhibition to allow transcription.

The apparent relief of inhibition by Gal4-VP16 shown here in an unfractionated yeast system corroborates previous findings in human and Drosophila systems (Croston et al. 1991; Workman et al. 1991) and extends the results in two respects. First, we have demonstrated an effect of Gal4-VP16 added to templates following nucleosome assembly, whereas Gal4-VP16 was present during assembly in previous work. Second, the loss of the Gal4-VP16 effect in a fractionated yeast system points to the involvement of additional components beyond the general initiation factors and RNA polymerase II. It remains to be seen whether transcription of a nucleosomal template involves the mediator required for transcriptional activation with naked DNA templates (Kelleher et al. 1990; Flanagan et al. 1991). Furthermore, it may be asked whether the mechanism of activation in these studies corresponds with that occurring in vivo. The yeast system should allow a test of this point, by the use of mutations in histone and nonhistone genes abrogating the transcriptional induction process (Durrin et al. 1991; Peterson and Herskowitz 1992). (The present findings were obtained with yeast transcription factors and templates assembled from rat liver histones; future studies will be directed toward the use of yeast histones as well.)

\section{Materials and methods}

Plasmids and DNA fragments

For construction of a chromatin template with a nucleosome on the TATA box (Fig. 1A), the large HincII-SphI fragment of pN2 (Lorch et al. 1987), containing a nucleosome positioning sequence, was ligated to the following oligonucleotide, containing residues -136 to -63 of the yeast $C Y C 1$ promoter with respect to the translation start site at +1 (McNeil and Smith 1985), to yield plasmid pN7:

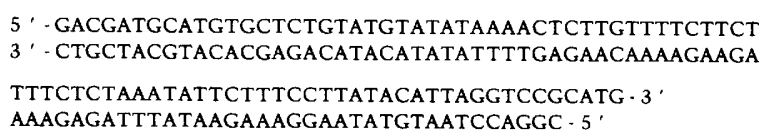

Cleavage of pN7 with EcoRI and AvaII gave the 193-bp fragment N7. A nucleosome was assembled on N7 and ligated to the 416-bp AvaII-BamHI fragment of p $\Delta \mathrm{CG}^{-}$(Lue at al. 1989), containing residues -66 to -35 of the $C Y C 1$ promoter fused to a 379-bp G-less cassette (Sawdogo and Roeder 1985b).

For construction of a chromatin template with a nucleosome on the transcription start sites (Fig. 1B), a fragment encoding 136 residues of G-less transcript was made by polymerase chain reaction with $\mathrm{p} \Delta \mathrm{CG}^{-}$and the following oligonucleotides: $5^{\prime}$ CCCGGCTCGAGGCATGTGCTCTGTATG-3' and $5^{\prime}$-GCGGCAAGCTTGTGAAGGAAGAGGGGG-3'. The reaction product was cleaved with $X h o I$ and HindIII and ligated with the large HindIII-SalI fragment of pUC19 to yield pN8. Cleavage of pN8 with HindIII and AvaII gave the 166-bp fragment N8. A nucle- osome was assembled on N8 and ligated to the 161-bp HindIIIAvaII fragment of pCZGal (Chasman et al. 1989), containing a 22-bp Gal4-binding oligonucleotide and residues -136 to -66 of the CYC1 promoter.

\section{Templates and transcription}

Nucleosomes were assembled, purified, and ligated to DNA fragments as described (Lorch et al. 1987). Ligation mixtures were used directly in transcription, without further purification. Amounts of DNA in nucleosomal templates refer to total N7 or N8, in either ligated or unligated form. Transcription was performed, and transcripts were analyzed as described (Lue et al. 1989; Sayre et al. 1992a). An unfractionated yeast RNA polymerase II transcription system was provided by whole-cell extract $(120 \mu \mathrm{g}$ of protein per reaction) prepared as described (Woontner et al. 1991). A reconstituted yeast RNA polymerase II transcription system comprised homogeneous general initiation factor-a (fraction VI, $1 \mu$ l; Sayre et al. 1992b), highly purified factor-b (Mono $S$ fraction, $2 \mu$; Sayre et al. 1992a), homogeneous recombinant yeast TFIID ( $4 \mathrm{ng}$ ), homogeneous factor-e (fraction VIII, $1 \mu \mathrm{l}$; Tschochner et al. 1992), highly purified factor-g (Mono $S$ fraction, $2 \mu 1$; Henry et al. 1992), and homogeneous RNA polymerase II (0.3 $\mu$ l; Sayre et al. 1992a). Gal4-VP16 was purified as described (Chasman et al. 1989).

\section{Acknowledgments}

We are grateful to Michael Sayre, Herbert Tschochner, Lynn Henry, and Daniel Chasman for generous provision of purified yeast RNA polymerase II and general initiation factors, and Gal4-VP16. This research was supported by grants from the National Institutes of Health.

The publication costs of this article were defrayed in part by payment of page charges. This article must therefore be hereby marked "advertisement" in accordance with 18 USC section 1734 solely to indicate this fact.

\section{References}

Bresnick, E.H., M. Bustin, V. Marsaud, H. Richard-Foy, and G.L. Hager. 1992. The transcriptionally-active MMTV promoter is depleted of histone H1. Nucleic Acids Res. 20: 273-278.

Chasman, D.I., J. Leatherwood, M. Carey, M. Ptashne, and R.D. Kornberg. 1989. Activation of yeast polymerase II transcription by herpesvirus VP16 and GAL4 derivatives in vitro. Mol. Cell. Biol. 9: 4746-4749.

Conaway, J.W. and R.C. Conaway. 1991. Initiation of eukaryotic messenger RNA synthesis. J. Biol. Chem. 266: 1772117724.

Croston, G.E., L.A. Kerrigan, L.M. Lira, D.R. Marshak, and J.T. Kadonaga. 1991. Sequence-specific antirepression of histone H1-mediated inhibition of basal RNA polymerase II transcription. Science 251: 643-649.

Durrin, L.K., R.K. Mann, P.S. Kayne, and M. Grunstein. 1991. Yeast histone $\mathrm{H} 4 \mathrm{~N}$-terminal sequence is required for promoter activation in vivo. Cell 65: 1023-1031.

Edwards, A.M., S.A. Darst, W.J. Feaver, N.E. Thompson, R.R. Burgess, and R.D. Kornberg. 1990. Purification and lipid layer crystallization of yeast RNA polymerase II. Proc. Natl. Acad. Sci. 87: 2122-2126.

Elgin, S.C.R. 1988. The formation and function of DNase I hypersensitive sites in the process of gene activation. $/$. Biol. Chem. 263: 19259-19262.

Feaver, W.J., O. Gileadi, and R.D. Kornberg. 1991. Purification 
and characterization of yeast RNA polymerase II transcription factor b. J. Biol. Chem. 266: 19000-19005.

Fedor, M.J., N.F. Lew, and R.D. Kornberg. 1988. Statistical positioning of nucleosomes by specific protein-binding to an upstream activating sequence in yeast. $\digamma$. Mol. Biol. 204: 109-128.

Felsenfeld, G. 1992. Chromatin as an essential part of the transcriptional mechanism. Nature 355: 219-224.

Flanagan, P.M., R.J. Kelleher III, M.H. Sayre, H. Tschochner, and R.D. Kornberg. 1991. A mediator for activation of RNA polymerase II transcription in vitro. Nature 350: 436-438.

Gross, D.S. and W.T. Garrard. 1988. Nuclease hypersensitive sites in chromatin. Annu. Rev. Biochem. 57: 159-197.

Grunstein, M. 1990. Histone function in transcription. Annu. Rev. Cell Biol. 6: 643-678.

Han, M. and M. Grunstein. 1988. Nucleosome loss activates yeast downstream promoters in vivo. Cell 55: 1137-1145.

Henry, N.L. M.H. Sayre, and R.D. Kornberg. 1992. Purification and characterization of yeast RNA polymerase II general initiation factor g. J. Biol. Chem. (in press).

Kelleher, R.J. III, P.M. Flanagan, and R.D. Kornberg. 1990. A novel mediator between activator proteins and the RNA polymerase II transcription apparatus. Cell 61: 1209-1215

Knezetic, J.A. and D.S. Luse. 1986. The presence of nucleosomes on a DNA template prevents initiation by RNA polymerase II in vitro. Cell 45: 95-104.

Kornberg, R.D. and Y. Lorch. 1991. Irresistible force meets immovable object: Transcription and the nucleosome. Cell 67: 833-836.

Laybourn, P.J. and J.T. Kadanoga. 1991. Role of nucleosomal cores and histone $\mathrm{H} 1$ in regulation of transcription by RNA polymerase II. Science 254: 238-245.

Lorch, Y., J.W. LaPointe, and R.D. Kornberg. 1987. Nucleosomes inhibit the initiation of transcription but allow chain elongation with the displacement of histones. Cell 49: 208210.

Lue, N.F., P. Flanagan, K. Sugimoto, and R.D. Kornberg. 1989. Initiation by yeast RNA polymerase II at the adenoviral major late promoter in vitro. Science 246: 661-664.

McNeil, J.B. and M. Smith. 1985. Transcription initiation of the Saccharomyces cerevisiae Iso-1-cytochrome $c$ gene. Multiple, independent T-A-T-A sequences. J. Mol. Biol. 187: 363378.

Peterson, C.L. and I. Hershkowitz. 1992. Characterization of the yeast SWI1, SWI2, and SWI3 genes, which encode a global activator of transcription. Cell 68: 573-583.

Ramsay, N. 1986. Deletion analysis of a DNA sequence that positions itself precisely on the nucleosome core. I. Mol. Biol. 189: 179-188.

Richard-Foy, H. and G.L. Hager. 1987. Sequence-specific positioning of nucleosomes over the steroid-inducible MMTV promoter. $E M B O$ I. 6: 2321-2328.

Sawadogo, M. and R.G. Roeder. 1985a. Interaction of a genespecific transcription factor with the adenovrius major late promoter upstream of the TATA box region. Cell 43: 165175.

- 1985b. Factors involved in specific transcription by human RNA polymerase II: Analysis by a rapid and quantitative in vitro assay. Proc. Natl. Acad. Sci. 82: 4394-4398.

Sayre, M.H., H. Tshochner, and R.D. Kornberg. 1992a. Reconstitution of transcription with five purified protein factors and RNA polymerase II from Saccharomyces cerevisiae. I. Biol. Chem. (in press).

Sayre, M.H., H. Tschochner, and R.D. Kornberg. 1992b. Purification and properties of Saccharomyces cerevisiae RNA polymerase II general intiation factor a. J. Biol. Chem. (in press).

Tschochner, H., M.H. Sayre, P.M. Flanagan, W.J. Feaver, and R.D. Kornberg. 1992. Yeast RNA polymerase II initiation factor e: Isolation and identification as the functional counterpart of human transcription factor IIB. Proc. Natl. Acad. Sci. (in press).

Wasylyk, B., G. Thevening, P. Oudet, and P. Chambon. 1979. Transcription of in vitro assembled chromatin by Escherichia coli RNA polymerase. $J$. Mol. Biol. 128: 411-440.

Williamson, P. and G. Felsenfeld. 1978. Transcription of histone-covered T4 DNA by Escherichia coli RNA polymerase. Biochemistry 17: 5695-5705.

Woontner, M., P.A. Wade, J. Bonner, and J.A. Jaehning. 1991. Transcriptional activation in an improved whole-cell extract from Saccharomyces cerevisiae. Mol. Cell. Biol. 11: 45554560 .

Workman, J.L. and R.G. Roeder. 1987. Binding of transcription factor TFIID to the major late promoter during in vitro nucleosome assembly potentiates subsequent initiation by RNA polymerase II. Cell 51: 613-622.

Workman, J.L., S.M. Abmayr, W.A. Cromlish, and R.G. Roeder. 1988. Transcriptional regulation by the immediate early protein of pseudorabies virus during in vitro nucleosome assembly. Cell 55: 211-219.

Workman, J.L., I.C.A. Taylor, and R.E. Kingston. 1991. Activation domains of stably bound GAL4 derivatives alleviate repression of promoters by nucleosomes. Cell 64: 533-544.

Workman, J.L., R.G. Roeder, and R.E. Kingston. 1990. An upstream transcription factor, USF (MLTF), facilitates the formation of preinitiation complexes during in vitro chromatin assembly. EMBO J. 9: 1299-1308. 


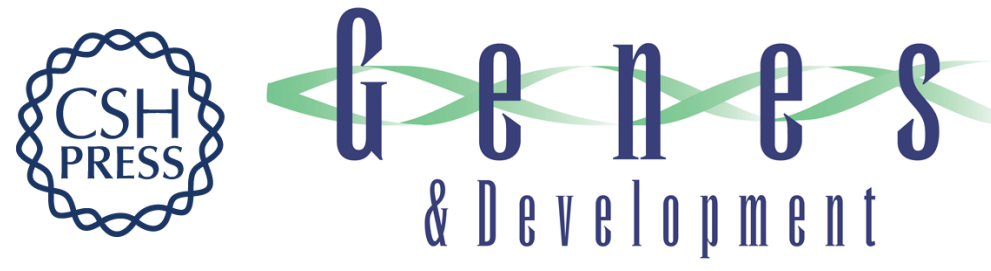

\section{Initiation on chromatin templates in a yeast RNA polymerase II transcription system.}

Y Lorch, J W LaPointe and R D Kornberg

Genes Dev. 1992, 6:

Access the most recent version at doi:10.1101/gad.6.12a.2282

References This article cites 33 articles, 10 of which can be accessed free at:

http://genesdev.cshlp.org/content/6/12a/2282.full.html\#ref-list-1

License

Email Alerting

Service

Receive free email alerts when new articles cite this article - sign up in the box at the top right corner of the article or click here.

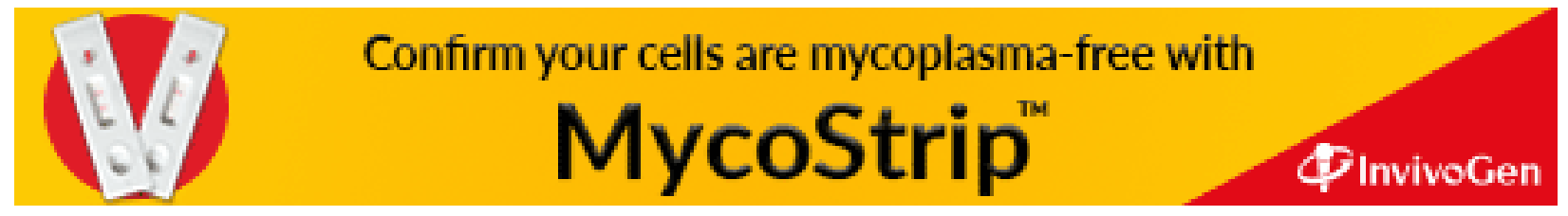

